\title{
Incorporation of steel slag and reclaimed asphalt into pavement surface layers
}

\author{
I. Rocha Segundo \& E. Freitas \\ Civil Engineering Department, University of Minho, Guimarães, Portugal
}

V. Castelo Branco

Transportation Engineering Department, Federal University of Ceará, Fortaleza, Brazil

S. Landi Jr.

Centre of Physics, University of Minho, Guimarães, Portugal, and Federal Institute Goiano, Rio Verde GO, Brazil

M. F. Costa \& J. Carneiro

Centre of Physics, University of Minho, Guimarães, Portugal

\begin{abstract}
There is an increasing concern about the recycling and reuse of wastes in different areas. This research aims to analyze the technical viability of the use of Reclaimed Asphalt Pavement (RAP) and Steel Slags (SS) for the composition of asphalt mixtures for surface layers. Therefore, three asphalt mixtures AC 10 were designed: without recycled materials $(\mathrm{R})$, with $30 \%$ of RAP (F) and with $30 \%$ of SS (A). They were mechanically and superficially assessed. Their water sensitivity and the permanent deformation were similar. The mixture A presented higher stiffness modulus and lower fatigue resistance when compared to the other ones. The best sound absorption and mechanical impedance found were for A and the worst ones were for F. Mixture A had smoother macrotexture if compared to the other mixtures. The asphalt mixtures had similar friction. It can be concluded that these wastes can be incorporated in asphalt mixtures for surface layers.
\end{abstract}

\section{INTRODUCTION}

Currently, it is undeniable to say that there is an increasing concern about natural resources depletion and environmental damages. In Paving Industry, most used raw materials, generally, come from non-renewable sources, i.e. aggregates and oil products, which are used as binders. On the other hand, there has been growing motivation for recycling wastes by incorporating them into asphalt mixtures. With this it is possible to obtain more ecological pavements, guaranteeing greater sustainability. In this context, the potential of some wastes has been studied: Steel Slags (SS), Construction and Demolition (C\&D) waste, tire rubber and some types of recycled polymers.

The main recycled waste incorporated in asphalt mixtures refers to the milled material from deteriorated asphalt pavement, which is called Reclaimed Asphalt Pavement (RAP). This material has already been studied in several replacement ratios in asphalt mixtures, and under different techniques of production, such as hot, warm and cold asphalt mixtures with or without additives. Its incorporation presents results which are even better than the ones found for conventional asphalt mixtures, while offering some benefits, for example, economical due to the use of aggregates and binder from RAP (Rocha Segundo et al., 2016). In the United States, the most recycled material is RAP, with more than 80 million tons per year, representing of about twice the other fourth most recycled wastes: paper, glass, plastic, and aluminum (Brosseaud, 2011). When discarded improperly, it can cause damages to the environment. With its use as a recycled material, it is possible to save money with the transport of virgin materials to the worksite, since RAP can be found on the roads to be paved around the urban perimeter, where quarries are often not located.

For the aged asphalt binder presented in RAP, its incorporation can provide more rigidity to the asphalt mixtures. On one hand, this can improve permanent deformation resistance, on the other hand, its use can decrease fatigue cracking resistance (Hussain and Yanjun, 2013). 
Other wastes from different sources have already been incorporated in the Paving Industry. It is worth mentioning the use of slags, the by-product of the Steel Industry. This residue has already been incorporated into asphalt mixtures, from base courses to surface layers. Generally, there are two types of slags produced by the industry: i) blast furnace: obtained directly from blast furnace; (ii) steel: resulting from the production of steel, obtained in electric furnaces and in oxygen converters. Some of its limitations are associated with its high density, causing higher transport costs, its high water absorption, which can increase the binder content, and its high expansion, requiring a curing period before the incorporation (Fakhri and Ahmadi, 2017).

Due to its metallic material content, mainly iron oxide $\left(\mathrm{Fe}_{2} \mathrm{O} 3\right)$, the SS present high electrical and thermal conductivity. Thus, asphalt pavements composed of this material, when irradiated by microwaves, can melt easier snow on its surface during the winter when compared to conventional asphalt pavements. Therefore, it can be portrayed as a new function of asphalt mixture, since this property is not considered as an essential one (Gao et al., 2017).

The literature points out that most of the researches are about the mechanical characterization of recycled asphalt mixtures, but not the functional (superficial) characterization (mainly taking into account the use of SS). Thus, this research aims to analyze the technical viability of the use of RAP and SS for the composition of asphalt mixtures for the surface layer of road pavements.

\section{MATERIALS}

\subsection{Aggregates and Bitumen}

In order to design the asphalt mixtures, two granite aggregates (fine aggregate $0 / 4 \mathrm{~mm}$ and course aggregate $4 / 10 \mathrm{~mm}$ ), filler, RAP $0 / 6 \mathrm{~mm}$ and SS 0/10 were used. Their main properties are presented in Table 1.

Table 1. Main properties of the natural and recycled aggregates.

\begin{tabular}{lccccc}
\hline Aggregate & $\begin{array}{c}\text { Particles } \\
\text { density } \\
\left(\mathrm{g} / \mathrm{cm}^{3}\right)\end{array}$ & $\begin{array}{c}\text { Water absorption } \\
(\%)\end{array}$ & $\begin{array}{c}\text { Micro-deval } \\
\text { abrasion loss } \\
(\%)\end{array}$ & $\begin{array}{c}\text { Los angeles } \\
\text { abrasion }(\%)\end{array}$ & $\begin{array}{c}\text { Binder } \\
(\%)\end{array}$ \\
\hline $4 / 10$ & 2.63 & 0.9 & 15 & 30 & - \\
$0 / 4$ & 2.67 & 0.5 & - & - & - \\
Filler & 2.71 & - & - & - & - \\
RAP 0/6 & 2.55 & 1.0 & - & - & 6.7 \\
SS 0/10 & 3.38 & 2.4 & 11 & 25 & - \\
\hline
\end{tabular}

The Form 2D, Sphericity, Angularity, and Surface Texture were characterized by Digital Image Processing (DIP) technique using Aggregate Image Measurement System (AIMS) (Table 2) (Al Rousan, 2004; Araujo, Bessa and Castelo Branco, 2015). By Their Form 2D, the aggregates 4/10, 0/4 and RAP were classified as elongated, while SS and filler were characterized as semicircular and semi-elongated respectively. All the coarse aggregates were characterized as moderate sphericity by the parameter sphericity. Considering the angularity, all the aggregates were sub-rounded. The surface texture of the materials was smooth for 4/10 and RAP and low rough for SS. Regarding all these parameters, it is possible to mark that the best aggregate characteristics is for SS.

The binder used was a commercial one named Elaster $13 / 60$ provided by Cepsa ${ }^{\circledR}$. The modified bitumen was classified as $35 / 50$ by penetration grade. The bitumen was characterized by (i) penetration of $50 \times 10^{-1} \mathrm{~mm}$ (EN 1426/2015); (ii) Brookfield viscosity of $349 \mathrm{cP}$ at $180{ }^{\circ} \mathrm{C}$ (EN 13302/2010); (iii) Softening Point of $64^{\circ} \mathrm{C}$ (EN 1427/2015). 
Table 2. Form, sphericity, angularity and texture characterization.

\begin{tabular}{lccc}
\hline Property & Aggregate & Average & Classification \\
\hline & $4 / 10$ & 8.0 & Elongated \\
Form 2D & //4 & 8.4 & Elongated \\
(fine) & RAP & 8.1 & Elongated \\
& SS & 7.9 & Semi-circular \\
& Filler & 8.3 & Semi-elongated \\
\hline \multirow{3}{*}{ Sphericity } & R/10 & 0.764 & Moderate sphericity \\
(coarse) & RAP & 0.737 & Moderate sphericity \\
& SS & 0.771 & Moderate sphericity \\
\hline & $4 / 10$ & 3619.0 & Sub-rounded \\
Angularity & O/4 & 3911.4 & Sub-rounded \\
(fine and & RAP & 3825.5 & Sub-rounded \\
coarse) & SS & 3554.1 & Sub-rounded \\
& Filler & 2466.3 & Sub-rounded \\
\hline Surface & $4 / 10$ & 175.3 & Smooth \\
Texture & RAP & 202.7 & Smooth \\
(coarse) & SS & 345.4 & Low roughness \\
\hline
\end{tabular}

\subsection{Asphalt Mixtures}

Three asphalt mixtures were designed by Marshall design method: i) R: reference mixture, ii) F: recycled mixture with $30 \%$ of RAP, iii) A: recycled mixture with $30 \%$ of SS. The asphalt mixtures have the same gradation and almost the same content of binder, of about 5.5\%. Table 3 shows the composition of the asphalt mixtures, binder contents, Bulk Density (BD), Maximum Bulk Density (MBD) and Void Content (VC).

Table 3. Macrotexture and friction results.

\begin{tabular}{lcccccccccc}
\hline $\begin{array}{l}\text { Asphalt } \\
\text { Mix }\end{array}$ & $\begin{array}{c}\% \\
4 / 10\end{array}$ & $\begin{array}{c}\% \\
0 / 4\end{array}$ & $\begin{array}{c}\% \\
\text { Filler }\end{array}$ & $\begin{array}{c}\% \\
\text { RAP } \\
0 / 6\end{array}$ & $\begin{array}{c}\% \\
\text { SS } \\
0 / 10\end{array}$ & $\begin{array}{c}\% \\
\text { binder }\end{array}$ & $\begin{array}{c}\% \text { virgin } \\
\text { binder }\end{array}$ & MBD $\left(\mathrm{g} / \mathrm{cm}^{3}\right)$ & $\mathrm{BD}\left(\mathrm{g} / \mathrm{cm}^{3}\right)$ & VC $(\%)$ \\
\hline $\mathrm{R}$ & 68 & 28 & 4 & - & - & 5.5 & 5.5 & 2.428 & 2.305 & 5.1 \\
\hline $\mathrm{F}$ & 67 & - & 3 & 30 & - & 5.4 & 3.5 & 2.446 & 2.334 & 4.6 \\
\hline $\mathrm{A}$ & 42 & 25 & 3 & - & 30 & 5.4 & 5.5 & 2.676 & 2.569 & 4.0 \\
\hline
\end{tabular}

\section{METHODS}

\subsection{Mechanical Characterization}

In order to characterize the asphalt mixture from a mechanical point of view, water sensitivity, permanent deformation, stiffness modulus, and fatigue resistance were assessed. The water sensitivity was evaluated by Indirect Tensile Strength Ratio (ITSR) test (EN 12697-12). The ratio between the wet samples (ITSw) and the dry samples (ITS) was calculated and defined as ITSR. The permanent deformation resistance of the asphalt mixtures was assessed by the Wheel Tracking Test (WTT) (EN 12697-22). The deformation curve versus cycle and the maximum rutting of the asphalt mixtures will be compared. For the stiffness modulus, the asphalt mixtures were assessed by the four-point bending test configuration (EN 12697-26) for different frequencies and temperatures. The master curve stiffness versus frequency $(\mathrm{Hz})$ will be compared at $20{ }^{\circ} \mathrm{C}$. Considering the fatigue resistance (EN 12697-24), the samples at $20{ }^{\circ} \mathrm{C}$ are submitted 
to sinusoidal loading at $10 \mathrm{~Hz}$, in strain control mode of loading. The relationship between the strain level versus the number of cycles will be presented.

\subsection{Superficial Characterization}

In order to characterize superficial properties of the asphalt mixtures, Mean Profile Depth (MPD), British Pendulum, sound absorption, and mechanical impedance tests were carried out. The same samples of WTT were used to characterize superficial properties. The macrotexture was assessed by MPD. Profiles of $25 \times 25 \mathrm{~cm}^{2}$ surface were acquired by a device equipped with a laser, and the MPD was calculated (ISO 13473-1:2019). The device can acquire profiles every $0.2 \mathrm{~mm}$ with a vertical resolution up to $0.01 \mathrm{~mm}$. The baseline of the profiles is divided by half of the length, and the average of their two peak heights is used to calculate the MPD. To access the friction, British Pendulum test was carried out (EN 13036-4).

Related to tire-road noise, for sound absorption, a self-made impedance tube with $80 \mathrm{~mm}$ of diameter utilizing the two-microphone arrangement was used (Freitas et al., 2014). A graph of absorption versus frequency (between 500 and $2000 \mathrm{~Hz}$ ) will be presented. For mechanical impedance, damping is a measure for determining the capacity of the structure to dissipate energy. An accelerometer was bonded to the specimen and it was submitted to a hammer impact in the opposite side. The Graph damping versus frequency $(\mathrm{Hz})$ will be presented. The configuration for the last two tests of noise indicators can be seen on Freitas et al. (2014).

\section{RESULTS}

The asphalt mixtures were mechanically characterized by water sensitivity, permanent deformation and fatigue resistance tests. The results of the water sensitivity test are shown in Table 4 . On the one hand, the ITS of the recycled asphalt mixtures increased by $44 \%$ and $34 \%$ for those ones composed of RAP (F) and SS (A), respectively. The ITSw also increased, 37\% and $35 \%$ for the same mixtures, respectively. On the other hand, the ITSR (water sensitivity) maintained for A but decreased 5\% for F. All the asphalt mixtures respected the minimum value of ITSR $(80 \%)$ required for Portuguese asphalt mixtures for the top layer of road pavements.

Table 4. Water sensitivity results.

\begin{tabular}{|c|c|c|c|c|c|c|}
\hline $\begin{array}{l}\text { Asphalt } \\
\text { Mix }\end{array}$ & $\begin{array}{c}\% \text { RAP } \\
0 / 6\end{array}$ & $\begin{array}{c}\% \mathrm{SS} \\
0 / 10\end{array}$ & $\begin{array}{l}\mathrm{VC} \\
(\%)\end{array}$ & $\begin{array}{c}\text { ITS } \\
(\mathrm{MPa}) \\
\end{array}$ & $\begin{array}{l}\text { ITSw } \\
(\mathrm{MPa})\end{array}$ & $\begin{array}{r}\text { ITSR } \\
(\%) \\
\end{array}$ \\
\hline $\mathrm{R}$ & - & - & 5.1 & 1.47 & 1.35 & 92 \\
\hline $\mathrm{F}$ & 30 & - & 4.6 & 2.12 & 1.84 & 87 \\
\hline A & - & 30 & 4.0 & 1.97 & 1.82 & 92 \\
\hline
\end{tabular}

For the permanent deformation (Figure 1a), at the end of the test, R, F, and A mixtures respected the maximum value considering the Portuguese requirements $(20 \mathrm{~mm})$ and deformed $1.86,1.93$ and $2.00 \mathrm{~mm}$. The recycled asphalt mixtures had similar behavior. $\mathrm{F}$ and $\mathrm{R}$ mixtures, respectively, deformed $4 \%$ and $8 \%$ more than the conventional AC 10. It can be concluded that the asphalt mixtures had a similar behavior considering the permanent deformation.

Regarding the results of the master curve of stiffness modulus at $20^{\circ} \mathrm{C}$ (Figure $1 \mathrm{~b}$ ), $\mathrm{R}$ (reference mixture), F (composed of 30\% of RAP) and A (composed of 30\% of SS) had values between 201 and 10,192 $\mathrm{MPa}, 858$ and 14,504 $\mathrm{MPa}, 251$ and 12,143 $\mathrm{MPa}$, respectively. Thus, considering the low frequencies, on the one hand, A mixture had similar moduli when compared to R. On the other hand, F mixture had stiffness modulus of about 4 times higher than $\mathrm{R}$ for the lowest frequency. At high frequencies, the stiffness moduli of R and A were similar and the difference between the results of $\mathrm{F}$ and $\mathrm{R}$ was lower than that one found at low frequencies. $\mathrm{F}$ had stiffness modulus about 1.4 times higher than $\mathrm{R}$ for the highest frequency. In general, $\mathrm{A}$ and $\mathrm{R}$ had similar results, and $\mathrm{F}$ had higher values. Probably this resulted from the aged binder of the RAP that composed F. Its content was $1.9 \%$. For the fatigue resistance (Figure 1c), the 
strain for $\mathrm{N}=10^{6}$ cycles was $339 \times 10^{-6}, 262 \times 10^{-6}$ and $317 \times 10^{-6}$ for $\mathrm{R}, \mathrm{F}$, and $\mathrm{A}$, respectively. A and $\mathrm{R}$ had similar curves and $\mathrm{F}$ presented lower results. It can be concluded by the mechanical results that the asphalt mixture that used SS as aggregate (A) presented superior mechanical results. Probably, this fact is related to the use of the aged binder from RAP provided higher stiffness for the mixture, contributing to lower fatigue resistance and higher stiffness modulus.

Also, the asphalt mixtures were superficially characterized by sound absorption and mechanical impedance, macrotexture and friction. Considering the assessments related to tire-road noise, mechanical impedance, and sound absorption, the results are presented in Figure 1d. For sound absorption, the average value was $0.18,0.16$ and 0.20 for $\mathrm{R}, \mathrm{F}$, and $\mathrm{A}$, respectively. Although the asphalt mixtures did not have a peak of maximum sound absorption within the interest frequencies, the best absorption was for A and the worst was for F. For damping, the investigated asphalt mixtures had 2 peaks. The first one was between 418 and $550 \mathrm{~Hz}$ and the second one was from 1,770 to $2,125 \mathrm{~Hz}$. The same trend for sound absorption was reported. The best damping was found for $\mathrm{A}$ and the worst one for $\mathrm{F}$.

For the macrotexture characterization, MPD was carried out and for friction characterization, the British Pendulum Test was used (Table 5). Analyzing the macrotexture, the mixture A had a macrotexture of about 17\% smoother than the other mixtures. Regarding friction, A had 7\% lower PTV and F had a similar PTV when compared to that of the R. Considering the superficial analysis, the best results for macrotexture and friction of the recycled asphalt mixtures is for F (30\% RAP), but, considering the noise indicators, sound absorption and mechanical impedance, mixture A ( $30 \% \mathrm{SS})$ presented the best results.

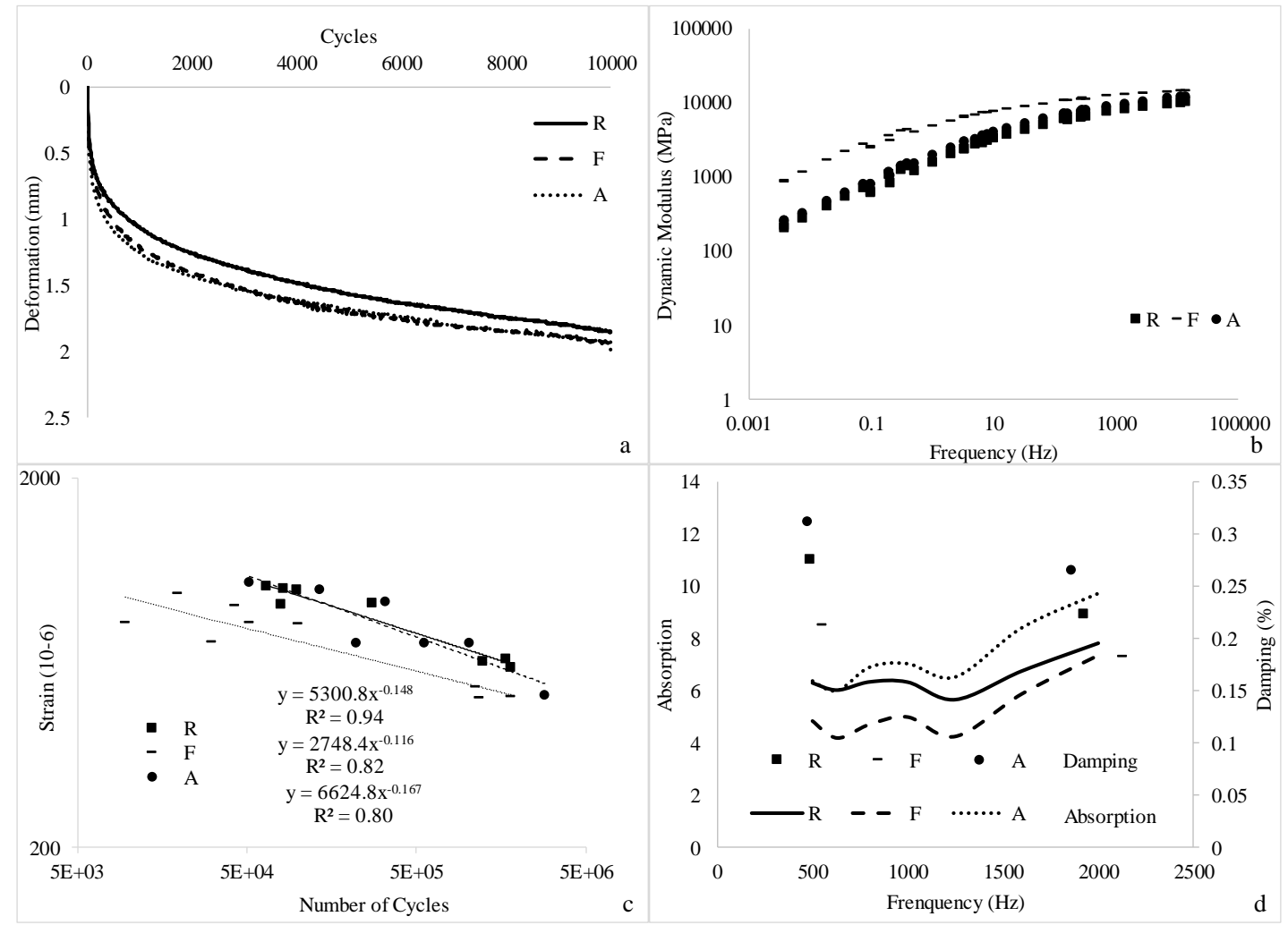

Figure 1. a) Permanent Deformation, b) Dynamic Modulus, c) Fatigue and d) Absorption and Damping 
Table 5. Macrotexture and friction results.

\begin{tabular}{lcc}
\hline Asphalt Mix & MPD (mm) & British Pendulum Value (PTV) \\
\hline $\mathrm{R}$ & 1.3 & 61 \\
$\mathrm{~F}$ & 1.3 & 60 \\
$\mathrm{~A}$ & 1.1 & 57 \\
\hline
\end{tabular}

\section{CONCLUSIONS}

This research aimed to analyze the viability of the use of RAP and SS in the composition of asphalt mixtures for surface layers. Three asphalt mixtures were designed, and mechanically and superficially characterized: without wastes (R), with $30 \%$ of RAP (F) and with $30 \%$ of SS (A). Based on the results of this research, the following conclusions can be drawn:

- ITS and ITSw of the recycled asphalt mixtures increased when compared to the conventional mixture, R. The water sensitivity of the asphalt mixtures was similar. All the asphalt mixtures had similar permanent deformation as well. In general, A and $\mathrm{R}$ had similar results of stiffness modulus, and $\mathrm{F}$ was stiffer. $\mathrm{A}$ and $\mathrm{R}$ had a similar fatigue curve and $\mathrm{F}$ had lower fatigue resistance. Probably, these results were due to the aged binder of RAP that composes F. Stiffer binder conducted to a stiffer asphalt mixture and to lower fatigue resistance.

- Regarding the surface characterization, the best absorption and mechanical impedance found was for A and the worst was for F. F and R had the same value of MPD (macrotexture). The mixture A had smoother macrotexture if compared to R and F. Regarding the friction results, the asphalt mixtures had similar PTV values.

Considering mechanical results, the best asphalt mixture was A (30\% SS). Regarding the superficial analysis, the best macrotexture and friction results of the recycled asphalt mixtures was for $\mathrm{F}$ (30\% RAP), but, considering the noise indicators, sound absorption and mechanical impedance, the best one was A. Thus, probably, mix A is more resistant and quieter than F, but $\mathrm{F}$ is safer than A. The aggregate characteristics of SS contributed to better mechanical results comparing to those ones observed for F. The use of SS did not impact the asphalt mixture properties significantly, differently of the use of RAP that conducted to lower fatigue resistance. Some superficial benefits were observed with the use of SS considering the noise indicators. By the fact that the recycled asphalt mixtures respected the characterization requirements, it can be concluded that SS and RAP can be used in asphalt mixtures for surface layers.

\section{REFERENCES}

Al Rousan, T.M. 2004. Characterization of aggregate shape properties using a computer automated system. Ph.D. Thesis, Texas A\&M University.

Araujo, V.M.C., Bessa, I.S. \& Castelo Branco, V.T.F. 2015. Measuring skid resistance of hot mix asphalt using the aggregate image measurement system (AIMS). Construction and Building Materials, 98 : 476-481.

Brosseaud, Y. 2011. Recycling of asphalt mixtures: evolution after 20 years and the current situation of France (in Portuguese language). In: $3^{\circ}$ Salão de Inovação ABCR - $7^{\circ}$ Congresso Brasileiro de Rodovias e Concessões. Foz do Iguaçu.

Fakhri, M. \& Ahmadi, A. 2017. Recycling of RAP and steel slag aggregates into the warm mix asphalt: A performance evaluation. Construction and Building Materials, 147: 630-638.

Freitas, E.F. Rodrigues, J.D., Rocha, J.A. \& Silva, H.M.R.D. 2014. Innovative low noise surfaces: comparison of damping and absorption. In: International Congress on Noise Control Engineering, Melbourne: Australian Acoustical Society $(A A S)$.

Gao, J. Sha, A., Wang, Z., Tong, Z. \& Liu, Z. 2017. Utilization of steel slag as aggregate in asphalt mixtures for microwave deicing. Journal of Cleaner Production, 152: 429-442.

Hussain, A. \& Yanjun, Q. 2013. Effect of reclaimed asphalt pavement on the properties of asphalt binders. Procedia Engineering, 54: 840-850.

Rocha Segundo, I.G. Castelo Branco, V.T.F., Vasconcelos, K.L., Holanda, A.S. 2016. Hot mix recycled asphalt with the incorporation of a high percentage of reclaimed asphalt pavement as an alternative to high modulus layer (in Portuguese language). Transportes, 24(4): 85-94. 